\title{
Retrospective Study of Tegumentary Leishmaniasis in Burkina Faso, from 2012 to 2016
}

\author{
Patindoilba Marcel Sawadogo $0^{1,2 *}$, Kiswendsida Thierry Guiguemdé2,4, Adama Zida 1,2, Nina korsaga/Somé2,3, \\ Ibrahim Sangaré ${ }^{5,6}$, Sanata Bamba ${ }^{5,6}$, Salimata Kiemdé', Rasmata Ouédraogo/Traorée, \\ 'Parasitology-Mycology Service, Yalgado Ouédraogo University Hospital Center, Ouaga, Burkina Faso \\ ${ }^{2}$ Training and Research Unit in Health Sciences, Ouaga University 1 Professor Joseph Ki-Zerbo (UO1 / PrZKZ), Ouagadougou, Burkina Faso \\ ${ }^{3}$ Dermatology-Venereology service, Yalgado Ouédraogo University Hospital Center, Ouaga, Burkina Faso \\ ${ }^{4}$ Parasitology-Mycology Service, Charles de Gaulle University Hospital Center, Ouagadougou, Burkina Faso \\ Institute of Health Sciences, Nazi Boni University, Bobo Dioulasso, Burkina Faso \\ ${ }^{6}$ Parasitology-Mycology Service, Souro Sanou University Hospital Center, Bobo Dioulasso, Burkina Faso
}

\section{Article Info}

\section{Article Notes}

Received: June 21, 2019

Accepted: August 31, 2020

\section{*Correspondence:}

Patindoilba Marcel Sawadogo, University Ouaga 1 Pr Joseph

Ki-Zerbo, O3 BP 7022 Ouagadougou 03, Burkina Faso;

Email: sawadogopmarcel@yahoo.fr.

C 2020 Sawadogo PM. This article is distributed under the terms of the Creative Commons Attribution 4.0 International License.

\section{Key words}

Retrospective

Leishmaniasis

Tegumentary

Ouagadougou

Burkina Faso

\section{Abstract}

Background: In Burkina Faso, the first cases of tegumentary leismaniasis were reported in 1960. But it was not until the 1990s that the disease was really known by the Burkinabè with the epidemic that Ouagadougou experienced at that time. Since 2000, the disease has become neglected. However, the frequency of cases diagnosed in hospitals suggests that tegumentary leismaniasis is still endemic in Ouagadougou. Hence the present study whose purpose and assess the current state of the disease in the city of Ouagadougou from 2012 to 2016 .

Methods: We conducted a descriptive study on retrospective data collected from January 2012 to December 2016 in different hospitals in the city of Ouagadougou. Data were collected from clinical and laboratory registers.

Results: a total of 96 parasitologically-confirmed cases were identified. Clinical forms were mentioned in 43 patients. Localized cutaneous leishmaniasis was the most common form $25 / 43$ (58.14\%), followed by mucocutaneous leishmaniasis $8 / 43(18.60 \%)$, diffuse cutaneous leishmaniasis $7 / 43(16.28 \%)$ and finally pseudo-leprosy Leishmaniasis $3 / 43$ (6.98\%). The Leishmaniasis / HIV association was found in 15 patients/96 (15.63\%). The parasitological examination in search of amastigote forms had a positivity rate of 92/209 $(44.02 \%)$. Meglumine antimoniate (Glucantime ${ }^{\circledR}$ ), the WHO reference drug, was the most prescribed 35/42 (83.33\%).

Conclusion: Tegumentary Leishmaniasis still exists in Ouagadougou. Thus, precautions must be taken to avoid an upsurge of cutaneous Leishmaniasis in Ouagadougou.

\section{Introduction}

Leishmaniasis are infectious diseases caused by the parasitism of mononuclear phagocyte system cells by flagellate protozoa belonging to the genus Leishmania. These parasites are transmitted by dipteran insects of genus of Phlebotomus in the Old World and Lutzomyia in the New World ${ }^{1,2}$. In Ouagadougou, the leishmania specie encountered in cutaneous leishmaniasis is Leishmania major. The vector sandfly species has still not been identified ${ }^{3,4}$. Clinically there are three types of Leishmaniasis depending on the parasite species and the immune status of the host: visceral Leishmaniasis, cutaneous Leishmaniasis, mucocutaneous Leishmaniasis. Leishmaniasis occur in tropical and subtropical areas of 98 countries, including 72 developing countries and 350 million people are at risk of contracting the disease ${ }^{5,6,7}$. Leishmaniasis is a global public health problem, with an estimated 
prevalence of 12 million cases ${ }^{8,9}$. The annual incidence as for it, is increasing in the world and would be between 1.5 to 2 million $^{6}$. According to WHO, Leishmaniasis ranks ninth among the thirteen most important tropical diseases.

In Burkina Faso, the first cases were notified in 1960 by Oddou ${ }^{1}$. The only focus of integumentary leishmaniasis with parasitological confirmation in the literature is that of Ouagadougou in the center of Burkina Faso. But Andona et $a l$ in 2016, Konaté et al en 2020, reported another focus in Larama located in the West of Burkina Faso in a study conducted since 2013. In addition, Sangaré et al reported a detection of Leishmania infantum for the first time in Burkina Faso in domestic dogs, in 2016. This species of leishmania is responsible for visceral leishmaniasis, thus suggesting the probable presence of a human case of visceral leihsmaniasis in Burkina, although this type of leishmaniasis has not yet been described in Burkina Faso $^{10,11 .}$

The last study on cutaneous Leishmaniasis in the city of Ouagadougou was conducted by Sawadogo in 2012, where 2,608 cases were recorded for the period from 2006 to $2012^{3}$. Since this last study in 2012 , there is a lack of updated knowledge on tegumentary Leishmaniasis in the city of Ouagadougou. However, the disease seems to be experiencing an upsurge as evidenced by the numerous requests for laboratory examinations and multiple relapses. It is in this context that we conducted this study to update the data on tegumentary Leishmaniasis since 2012.

\section{Methods}

The aim was to evaluate the current state of the disease in the city of Ouagadougou from 2012 to 2016. The city of Ouagadougou is the administrative capital of Burkina Faso. Located in the heart of Kadiogo province, Ouagadougou is an urban agglomeration that covers an area of 51,800-hectare, 1915102 inhabitants (2012 estimate ${ }^{12}$. the city has three third level centers and 5 health districts. The study concerned all health centers in the city where the clinical and laboratory diagnosis of tegumentary Leishmaniasis is made. The data were located in all the 5 health districts and 3 public or semipublic referral centers and provided a general overview of the state of the tegumentary Leishmaniasis of the city of Ouagadougou. The factors explaining the LC epidemics in Ouagadougou are still at the stage of hypotheses. The role of displacement of urban populations to peripheral areas has also been implicated in the epidemic ${ }^{3}$. Rodents of the genus Mastomys $s p$, Taterillus $s p$ have been captured infected, suggesting their role as reservoir of parasites in epidemiology ${ }^{3}$.

\section{Patients of the study}

The study population consisted of suspected patients of tegumentary Leishmaniasis who consulted in the health centers concerned by the study between 2012 and 2016 . Only microscopically confirmed cases were taken into consideration for the study.

\section{Inclusion criteria}

All suspected cases of integumentary leishmaniasis were included, regardless of sex, age and ethnicity, having undergone a biological diagnosis at the ParasitologyMycology laboratories of the CHU-YO and Sainte Elisabeth.

\section{Data collection process}

We performed a full collection of data on tegumentary leishmaniasis contained in the existing records of the referred health centers and laboratories consulted

Data collection sources consisted of: Clinical records of patients, records of consultations and hospitalizations, hard disks containing electronic patient records, laboratory records.

The collection was carried out in two stages: the first stage is carried out in the laboratories of hospitals Parasitology concerned, and was to collect all suspected cases of tegumentary leishmaniasis having been confirmed by an parasitological examination between 2012 and 2016 . The second stage took place in the Dermatology-Venerology departments of the concerned hospitals. In these services, clinical and sociodemographic characteristics of the patients were collected from clinical records.

\section{Data analysis}

The collected data were analyzed and processed using the software Epi Info version 7.2.1.0 and Microsoft Excel 2016.

\section{Results}

From 2012-2016, 213 patients were considered suspicious and 96 were parasitologically confirmed. Of the 96 confirmed cases, the sex ratio was 1.4 (Male/female). Age was mentioned in 84 patients. The average age was $30.82 \pm 21$ years with extremes of 1 to 82 years. The 21 to 30 age group was the most represented at 22/84 (26.19\%). And 15/96 (15.63\%) were people living with HIV.

Of 209 dermal juice smears for the search for Leishmania $s p, 92$ were positive. A positivity rate was $44.02 \%$. The remaining 4 cases (for a total of 96 cases) were confirmed by histology.

\section{Distribution of confirmed tegumentary leishmaniasis cases from from 2012 to 2016}

The distribution of the number of tegumentary Leishmaniasis is shown in Figure 1. The highest number was observed in 2012 with 32/96 (33.33\%) and the smallest number was noted in 2016 with 13 cases. 


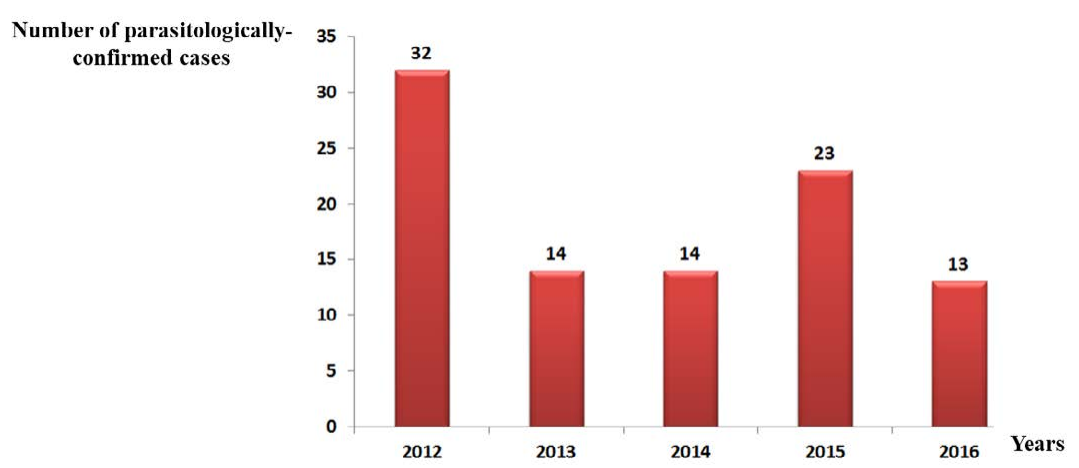

Figure 1: Distribution of tegumentary cases by year

The axis of ordinates shows the number of cases of tegumentary Leishmaniasis per year. The number is displayed in steps of 5 ranging from 0 to 25 cases. While the $x$-axis shows the years: from 2012 to 2016 . The curve in the figure shows a progressive trend in the number of tegumentary Leishmaniasis since 2013. During the period of 2012-2016 there was an oscillation of cases, with 2012 concentrating the largest number, reducing cases in 2013 and 2014, rising again in 2015 and reducing in 2016, so talking only about a progressive trend from 2013 leaves the analysis of the period impaired.

\section{The types of tegumentary leishmaniasis}

The type of Leishmaniasis was reported in 43 patients. The clinical types observed are dominated by cutaneous Leishmaniasis 25/43 (58.14\%). The other types observed were: mucocutaneous Leishmaniasis 8/43 (18.60\%), diffuse cutaneous leismmaniasis 7/43 (16.28\%), pseudoleprosy Leishmaniasis 3/43 (6.98\%).

\section{Topography of lesions}

Table 1: Distribution of topographic forms of lesions

\begin{tabular}{|l|c|c|}
\hline \multicolumn{1}{|c|}{ Types of lesions } & Numbers & Percentage (\%) \\
\hline Ulcerative crusty & 14 & 29,78 \\
\hline Papulo- nodular & 8 & 17,02 \\
\hline Exulcero-crusted & 6 & 12,76 \\
\hline papular & 4 & 8,51 \\
\hline Erythematous papular & 3 & 6,38 \\
\hline pseudo-lepromatous & 3 & 6,38 \\
\hline Pseudo-trichosique & 2 & 4,26 \\
\hline Papulo- crusty & 2 & 4,26 \\
\hline nodular & 2 & 4,26 \\
\hline Necrotic ulcerative & 1 & 2,13 \\
\hline ulcerous & 1 & 2,13 \\
\hline Nodulo-crusty & 1 & 2,13 \\
\hline Total & 47 & 100,00 \\
\hline
\end{tabular}

\section{Prescribed drugs}

Of the 96 confirmed cases, drugs used to treat tegumentary Leishmaniasis were reported in 42 cases. The prescribing frequencies are meglumine antimoniate $35 / 42$ (83.33\%), pentamidine diisethionate 3/42 (7.14\%), meglumine antimoniate and then pentamidine $3 / 42$ (7.14\%), fluconazole $1 / 42$ (2.39\%).

\section{Evolution of leishmaniasis lesions after treatment}

Progression was favorable in $19 / 42$ (45.24\%) of patients and relapses were observed in $3 / 42$ (7.14\%) of treated patients. Progression after treatment was not specified in 20/42 (47.62\%) of the patients treated.

\section{Discussion}

The fact that our study was retrospective, did not allow us to find, in some cases, all the data of the interrogation, the physical examination. To this is added the lack of parasitological confirmation of some cases, hence the reduction of the sample size to 96 confirmed cases. In addition, confirmation in the laboratory was limited to demonstrating the amastigote form without identification of the Leishmania species.

We found a sex ratio of 1.4. A male predominance was also noted in previous studies conducted in Burkina Faso in 2016 by Andonaba et al. $(1.08)^{10}$; in 2015 by Demba et al. in Chad (1.7) ${ }^{13}$; in Senegal in 2014 by Diallo (1.6) ${ }^{14}$. Two main factors could explain the male predominance. On the one hand, this is the predominance of men in the population of Ouagadougou ${ }^{12}$ and on the other hand, the heavy nighttime use of public spaces by men exposes them to the bite of sandflies. The average age of our patients was $30.82 \pm$ 21 years, with extremes of 1 year to 82 years. This finding was similar to that of Hajji in 2010 in Morocco, which noted an average age of 32 years with extremes ranging from 1 year to 85 years. The age groups of 10-14 and 15-49 years were the most represented ${ }^{15}$. Indeed, the population of this age group is the most active population, therefore the most exposed to vector transmission of the disease.

HIV / Leishmaniasis co-infection was found in 15/96 patients (15.63\%). Guiguemde et al. in 2002 in Burkina Faso, which reported a co-infection rate of Leishmaniasis / HIV, 13\% ${ }^{4}$. Nikiéma in Burkina Faso in 2002, who found a co-infection frequency of $14.3 \%{ }^{16}$. Niamba et al. in 2006 , during their study on cutaneous Leishmaniasis in HIV- 
infected patients, which identified 32 cases of Leishmaniasis / HIV co-infection ${ }^{17}$. Immunosuppression would promote the evolution of tegumentary leishmaniasis by increasing susceptibility to Leishmania infection in HIV patients and by worsening of the clinical condition with co-infection ${ }^{17}$.

The 2012 cases are more than double the cases of 2013, 2014 and 2016, they are divergent, with no occurrence of regularity. The smallest frequency is observed in 2013 and the high frequency is observed in 2012. These results show that even if Leishmaniasis is still prevalent in Ouagadougou, the figures seem to be still much lower than at the beginning of the 2000s. Indeed in the late 1990s and early 2000s, following the development of the Ouaga 2000 district, the city of Ouagadougou has experienced an epidemic of tegumentary leishmaniasis, hence the name "Ouaga 2000 disease" given to tegumentary Leishmaniasis in Burkina Faso ${ }^{18}$ whose main focus remains the city of Ouagadougou.

There are many reasons for the decrease in the number of cases: the extinction of the epidemic focus of the 1990s, early 2000 , by the reduction of the reservoir population and the management of cases at the time. The sensitization of the population of Ouagadougou on the modes of transmission and on the management of the disease.

However, it should be noted that despite the decrease in the number of cases, tegumentary leishmaniasis continues to be endemic in Ouagadougou. This persistence in Ouagadougou is believed to be due to several factors, which are: the absence of national guidelines to fight this disease. In fact, although the control of leishmaniasis is integrated into the vast program of neglected tropical diseases control, no strategy to control leishmaniasis has yet been implemented in Burkina Faso ${ }^{3}$. There is also the importance of the rodent population, a reservoir of leishmania, in the outskirts of the city of Ouagadougou due to the high urbanization of the city. Finally, the precarious sanitation of the city promotes the proliferation of sandflies, and thereby the transmission of the disease. The role of displacement of urban populations to peripheral areas has also been implicated in the epidemic ${ }^{3}$.

We noted a polymorphism of tegumentary Leishmaniasis. Localized Cutaneous Leishmaniasis (LCL) $15 / 43(58,14 \%)$ was the most common, followed by Cutaneous-Mucous Leishmaniasis (LCM) 8/43 (16,28\%), Diffuse Cutaneous Leishmaniasis (LCD) 7/43 (16,28\%), and Pseudo-Lepromatous Leishmaniasis (LPL) 3/43 (6,98\%). Cutaneous and mucosal Leishmaniasis is rarely reported in Africa [9]. The fact that this form is quite common in Ouagadougou raises a certain number of hypotheses. Among others, a particularly virulent zymodeme would circulate in Ouagadougou. And as a prospect a fundamental study on isolated strains of Leishmania could confirm or invalidate this hypothesis.
We identified twelve (12) clinical forms, with a predominance of ulcerative-crustal forms of $29.78 \%$. This predominance of ulcerative-crustal forms (29.78\%) was different to that of $40.2 \%$ found by Bamba et al in Burkina Faso in $2006^{18}$, and that of $53.1 \%$ recorded by Kéita et al. in 2003 in Mali $^{19}$, and at the $48 \%$ rate observed by Hjira et al. in 2014 in Morocco. However, in all these studies as in ours, this ulcerative-crustal form was the predominant form. The predominance of these clinical forms in the present study is consistent with data from the literature where Leishmania major, the most commonly encountered species in Burkina Faso, produces ulcerative-crustal lesions ${ }^{10}$.

Our positivity rate was in agreement with the rate (48.6\%) found by Nikiéma in 2002 in Burkina Faso ${ }^{16}$. This positivity rate is very low compared to those found by Traoré et al. in Burkina Faso in 2001, by Jebbouri in Morocco in 2014, by Kéita in Mali in 2005, and by Demba et al. in Chad in 2015, which were respectively 53.8\%, $65 \%, 84 \%, 85 \%{ }^{13,17,20,21}$. The low positivity rate and the difference observed with those of these authors seem to reflect a remarkable discordance of clinical diagnosis and parasitological diagnosis in our study ${ }^{17}$.

But, this discrepancy could be explained by several factors: delay of consultation, bacterial superinfections of the lesions, taking of various medications including the traditional drugs ${ }^{17}$. However, a negative smear does not exclude the diagnosis in an endemic context with a strong clinical presumption.

Meglumine antimoniate (Glucantime $\AA$ ) was the most widely used tegumentary Leishmaniasis drug (83.33\%). Peri-lesional infiltration was performed in $25 / 42$ patients $(59.52 \%)$ and the parenteral route (MI) in $13 / 42$ patients (30.95\%). Pentamidine (pentacarinat $\AA$ ) was by far the second highest with $3 / 42$ (7.14\%) use. Our findings were similar to those of Hjira et al. in Morocco in 2014 ${ }^{19}$, Nikiéma in Burkina Faso in 2002 ${ }^{16}$, Diallo in Senegal in $2014^{14}$, and Bamba et al. in Burkina Faso in $2013^{9}$, who noted the use of meglumine antimoniate (Glucantime ${ }^{\circledR}$ ) as first-line therapy. This shows that there has been very little change in Leishmaniasis therapy ${ }^{21}$. Meglumine antimoniate is the standard treatment for tegumentary Leishmaniasis. However, this treatment exposes many side effects and resistance is increasingly reported in several countries ${ }^{21}$.

Progression under treatment was not emphasized in $47 \%$ of patients. It was favorable in $19 / 42$ (45.24\%) of the cases and was marked by recurrence under treatment with Glucantime $\AA$ in $3 / 42$ cases $(7.14 \%)$ thus raising probable cases of resistance of some of tegumentaire with antimonies. Cases of recurrence were mentioned by Nikiéma in Burkina Faso in 2002 (4 cases) ${ }^{16}$. 


\section{Conclusion}

At the end of our retrospective study on tegumentary leishmaniasis in the city of Ouagadougou from 2012 to 2016, it appears that the disease is still quite frequently encountered in Ouagadougou. Although the number of cases is significantly lower in the early 2000s, the fluctuating evolution of the number of cases from 2012 to 2016 raises fears of an epidemic outbreak of the disease. Precautions must be taken to avoid a new epidemic of tegumentary leihsmaniasis in Ouagadougou.

\section{References}

1. Oddou A. Leishmaniose cutanee en Haute Volta. Bull Soc Med Afr. 1960; 7: 28.

2. Mokni M, Del Giudice P, Dupin N. Dermatologie infectieuse. 5 edition Paris : Elsevier Masson. 2014.

3. Konate I, Sangare I, Zoungrana J, et al. Description d'un nouveau foyer epidemique de leishmaniose cutanee a Leishmania major à l'Ouest du Burkina Faso. Pan African Medical Journal. 2020; 35: 65. [doi: 10.11604/pamj.2020.35.65.20825]

4. Guiguemde RT, Sawadogo OS, Bories C, et al. Leishmania major and HIV co-infection in Burkina Faso. Trans R Soc Trop Med Hyg. 2003; 2: 97.

5. Alvar J, Velez ID, Bern C, et al. Leishmaniasis worldwide and global estimates of its incidence. PLoS One. 2012; 7(5): e35671.

6. Pierre A, Bernard-Alex G. Leishmanioses : actualites 2016. Med Trop. 2016.

7. Bastien $\mathrm{P}$, Lachaud L. Leishmanioses : biologie, clinique et therapeutique. EMC Mal Infect. 2016; 13: 3.

8. Assosiation Française des Professeurs de Parasitologie et Mycologie (ANOFEL). Leishmanioses : (C) UMVF - Université Médicale Virtuelle Francophone [En ligne]. 2014 http : //umvf.univnantes.fr/ parasitologie/ enseignement /leishmanioses / site/html/cours.pdf. accessed 02 juin 2017:

9. Bamba S, Barro-Traore F, Drabo MK, et al. Profil épidémiologique, clinique et therapeutique de la leishmaniose cutanee dans le Service de Dermatologie du Centre Hospitalier Universitaire de Ouagadougou. Rev Med Brux. 2013; 14: 39 .
10. Andonaba JB, Konate I, Diallo B, et al. La leishmaniose cutanee : un deuxieme foyer epidemique a Leishmania major au Burkina Faso. Ann Dermatol Venereol. 2016; 3: 24.

11. Sangare I, Djibougou AD, Yameogo BK, et al. First Detection of Leishmania infantum in Domestic Dogs from Burkina Faso (West Africa). Research Journal of Parasitology. 2016; 12(1): 27-32.

12. DGESS. Annuaire statistique 2016. Ministere de la Sante, Burkina Faso. 2016.

13. Demba Kodindo I, Baïndaou G, Tchonfinet M, et al. Etude retrospective de la leishmaniose cutanee a l'hopital de district d'Am Timan, Tchad. Bull Soc Pathol Exot. 2015; 10: 8 2.17.

14. Diallo K. leishmaniose cutanee : profil epidemiologique, clinique, therapeutique et evolutif [these : Med] Bamako : université des sciences des techniques et des technologies de Bamako. 2014; 8.

15. Hajji R. Le profil epidemiologique de la leishmaniose cutanée dans la province de Ouarzazate entre 2002-2009 [these : Med] Marrakech : universite cadi ayyad. $2010 ;(30)$.

16. Nikiema L. la leishmaniose tégumentaire : “ouaga 2000". Aspects cliniques, biologiques, evolution sous traitement par le glucantime, et particularites chez le sujet immunodeprime dans la ville de ouagadougou [Theese : Med] Ouagadougou : universite de Ouagadougou. UFR SDS. 2002 ; (9).

17. Niamba P, Traore A, Goumbri-Lompo 0 , et al. Leishmaniose cutanee chez les malades infectes par le VIH : aspects cliniques et therapeutiques. Ann dermatol venereol. 2006; 5: 42.

18. Traore KS, Sawadogo NO, Traore A, et al. Etude préliminaire de la leishmaniose cutanée dans la ville de Ouagadougou de 1996 a 1998. Bull Soc Pathol Exot. 2001; 1: 94.

19. Hjira N, Rachid F, Tarik M, et al. Aspects epidemiocliniques et evolutifs chez 157 cas de leishmaniose cutanee au Maroc. Pan African Medical Journal. 2014; 17: 272.

20. Jebbouri Y. Profil epidemio-clinique, therapeutique et evolutif de la leishmaniose cutanee (A propos de 52 cas) [these : Med] Fes : universite Sidi Mohammed Ben Abdellah de Fes. 2013; (94).

21. Keita S, Faye 0, Ndiaye HT, et al. Epidemiologie et polymorphisme clinique de la leishmaniose cutanée observee au CNAM. Mali Medical. 2003; $1: 2$. 